\title{
Connectedness Among Chilean Adolescents: Factor Analysis of the Hemingway Measure of Adolescent Connectedness
}

\section{La Conectividad Entre Adolescentes Chilenos: Un Análisis Factorial de la Hemingway Measure of Adolescent Connectedness}

\author{
Benedict T. McWhirter and Ellen Hawley McWhirter \\ University of Oregon
}

\begin{abstract}
The construct of connectedness was investigated among 390 Chilean adolescents using the Hemingway Measure of Adolescent Connectedness (Hemingway; Karcher, 2003). Participants were $7^{\text {th }}-12^{\text {th }}$ graders at an urban Santiago Catholic school. Results of a principal-axis exploratory factor analysis revealed an 11 factor structure that accounts for $61.92 \%$ of total explained variance of adolescent connectedness measured by the Hemingway, similar to results found in the adolescent samples in the United States. Two additional Hemingway subscales (connectedness to siblings and to boyfriend/girlfriend) are also described. Correlations between domains of connectedness and additional data obtained from these adolescents, their parents, and their teachers support the construct validity of the measure in this Chilean sample. Connectedness is an important protective factor among adolescents across many national contexts and the Hemingway is a promising measure for use with Chilean adolescents.
\end{abstract}

Keywords: connectedness, adolescents, measurement, risk factors, protective factors

Se examinó el constructo conectividad en 390 adolescentes chilenos en un colegio urbano y católico de Santiago. Mediante un análisis factorial exploratorio de la escala Hemingway Measure of Adolescent Connectedness (Hemingway, Karcher, 2003) se observó una estructura de 11 factores que da cuenta de un $61,92 \%$ de la varianza explicada de la conectividad de los adolescentes medida por la escala Hemingway, lo cual es muy similar a los resultados obtenidos en muestras de adolescentes estadounidenses. También se describen dos subescalas adicionales (la conectividad con los/las hermanos/as y con los/las pololos/as). Las relaciones entre los factores de conectividad y los datos reportados por los adolescentes, sus padres y profesores contribuyen también a la validez de constructo de la escala en esta muestra chilena. Para los adolescentes de distintos contextos culturales la conectividad es un factor importante de protección y la escala Hemingway es un instrumento de uso prometedor con adolescentes chilenos.

Palabras clave: conectividad, adolescentes, medición, factores de riesgo, factores protectores

Issues of autonomy and connection are at the forefront of development during adolescence (Beyers, Goossens, Vansant, \& Moors, 2003; Clark \& Ladd, 2000; Dwairy, Achoui, Abouserie, \& Farah, 2006; Grotevant \& Cooper, 1998; Huiberts, Oosterwegel, Vandervalk, Vollebergh, \& Meeus, 2006; Saraví, 2009). Connectedness is defined as the experience that occurs "when a person is actively involved with another person, object, group, or environment, and that involvement promotes a sense of comfort, well-being, and anxiety reduction” (Townsend \&

Benedict T. McWhirter and Ellen Hawley McWhirter, Counseling Psychology \& Human Services, University of Oregon, Eugene, Oregon, USA.

This research was supported in part by the US Department of State, Commission for the International Exchange of Scholars, via 2004 Fulbright Scholar Awards to Chile for Dr. Benedict T. McWhirter (Universidad del Desarrollo, Santiago, Chile) and Dr. Ellen Hawley McWhirter (Universidad de Chile, Santiago, Chile).

We thank Fabián Carreño, Edgard Blas, Victoria Parra, Evelyn Palma (Chile), and Karrie Walters (USA) for their contributions to this research study.

Correspondence concerning this article should be addressed to Benedict T. McWhirter, Counseling Psychology \& Human Services, 5251 University of Oregon, Eugene, Oregon, 97403-5251, USA. E-mail: benmcw@uoregon.edu 
McWhirter, 2005, p. 193). This definition is consistent with other literature that highlights both behavioral (e.g., involvement) and emotional (e.g., comfort) dimensions in understanding how adolescents experience different contexts and relationships (Barber \& Schluterman, 2008; Karcher \& Sass, 2010; Resnick et al., 1997).

In adolescent populations connectedness is measured by examining the different domains of an adolescent's life, including school, family, and social environments. While the evidence supports the importance of connectedness for adolescents, and its potential as a target of prevention efforts (e.g., Karcher \& Finn, 2005), the construct of connectedness has not been validated in many cultural and national contexts. One measure of youth connectedness, the Hemingway Measure of Adolescent Connectedness (Hemingway), has a number of benefits including its attention to multiple dimensions of connectedness. The purpose of the present study was to determine the factorial structure of the Hemingway among Chilean adolescents and demonstrate its construct validity. Doing so contributes to understanding universal and culturally specific aspects of connectedness and may provide a useful measurement tool for use with Chilean adolescents.

To understand the measurement of connectedness and the Hemingway, it is important to describe first the construct and its theoretical roots. The construct of adolescent connectedness emerges from adolescents' need for belongingness and relatedness. Karcher's (2003) manual on the construction of the Hemingway notes that it was built upon an interpretive-hermeneutic framework. Consistent with the interpretive framework, adolescent experiences of connection are considered to be shaped over time and, therefore, present and future time orientations are reflected in the measure's subscales (Karcher, 2003). The measure also reflects the hermeneutical notion that human beings are best understood via their interpretations of their connectedness to the world over time. The Hemingway also attends to youth's behavioral and affective experience of connectedness to conventional (family, religion, and school) and unconventional (peers, romantic partners, neighborhood, and self) worlds.

The development of specific Hemingway items draws from the self psychology concept (e.g., Kohut, 1977; Kohut \& Wolf, 1978) that healthy self development emerges through both the validation received within dyadic relationships and the experience of relationships with competent, protecting, and consistent others. When provided sufficient praise, empathy, and attention by significant others, youth learn to praise, esteem, and soothe themselves, the hallmark of self-development and mature forms of connectedness (see Karcher, 2003). Therefore, the Hemingway subscales are relational and contextual and designed to illuminate adolescents' behavior in terms of their ability to satisfy their need to belong through connectedness with people and places over time (Karcher, 2003).

Developmental principles within the ecological model (Bronfenbrenner, 1979) and prevention research also contribute to the conceptualization and measurement of connectedness. The ecological model highlights the importance of context in human development and the bidirectional influences that occur between the developing child/adolescent and his/her social worlds over time. The microsystems of family and school are independently important, interact within the mesosystem, and are affected by exosystemic features, such as poverty and public policy. All of these environments fall within the macrosystemic contexts that include cultural interactions and broader social values and biases. The importance of youth connections within these systems is reflected in the Hemingway measure through its subscales on the proximal contexts of family, school, and peers, as well as on more distal contexts of neighborhood/community and culture, as important worlds of youth connection (Karcher, 2003). These contexts were identified as central to adolescents in a series of focus groups conducted by Karcher (2003) as part of the subscale and item development.

Finally, Karcher (2003) aimed to develop a tool useful in assessing the effects of prevention intervention research, specifically, interventions designed to promote social development and to reduce problem behaviors. As a result, the scales include dimensions (such as Reading) that are not described explicitly in the literature upon which the theory is built, but that are central outcomes sought in prevention research and program development. To that end, the Hemingway was developed: 
to aid in the study of the consequences of disconnection (e.g., substance use, violence, and depression; e.g., see Hawkins, Catalano, \& Miller, 1992), as well as of the activities and attitudes that inform positive social development and reflect strengths in individuals and in communities (e.g., Clark \& Ladd, 2000; Grotevant \& Cooper, 1998; Lynch \& Cicchetti, 1998). (Karcher, 2003, p. 3)

A growing number of studies have examined relationships between connectedness and various risk and protective factors among adolescents in various national contexts. For example, von der Lippe and Amundsen (1998) found a relationship between connectedness and the quality of conflict negotiation in the families of adolescent girls in Scandanavia. Kumi-Kyereme, Awusabo-Asare, Biddlecom, and Tanle (2007) reported high levels of adolescent connectedness to family, adults, friends, school, and religion in Ghana, and recommend fostering connectedness as part of multifaceted efforts to promote optimal sexual and reproductive health. Karcher and Lee (2002) found that dimensions of connectedness were significantly and directly related to self-esteem among Taiwanese middle school students. In the United States, the National Longitudinal Study of Adolescent Health found that parent-family connectedness and perceived school connectedness were protective against seven out of eight measures of healthcompromising behaviors, including the adolescents' emotional distress, suicidal thoughts and behaviors, and violence (Resnick et al., 1997). These and other studies implicate the role of connectedness in patterns of risk behaviors among adolescents around the world. Moreover, promoting the connectedness of youth to their schools, their families, their own future, and to the world as a global community is central to healthy adolescent development and is a specific goal of many school-based and family-centered intervention programs in the Unites States and elsewhere (e.g., Dishion, Bullock, \& Kiesner, 2008; Evans et al., 2005; Grossman \& Bulle, 2006; Roth \& Brooks-Gunn, 2003; World Health Organization, 2003).

For youth in Latin America, Saraví (2009) emphasized the critical social importance of adolescent belongingness across the continent. More specific to Chile, there is clear evidence that the construct of belongingness or relatedness is meaningful, although the construct has not been measured specifically as connectedness. For example, Chilean adolescents report generally positive relationships within their families (Martinez, Cumsille, \& Thibaut, 2006) and in particular report greater satisfaction in their relationships with their mothers than with their fathers, although their level of satisfaction with both is quite high (Herrera, 2007). Chilean adolescents are not highly likely to talk with their parents about topics such as religion, sexuality, and what they do in their free time. However, among those that do, they are more likely to talk with their mothers than their fathers about such matters. Family problems identified by Chilean youth ages 15-19 include lack of time together (46.5\%), lack of communication (37.5\%), and poor parent/child relationships (20.5\%). Most young Chileans (82\%) believe that their mothers have dedicated sufficient time to them, while $59 \%$ believe that their fathers have given them enough time (Herrera, 2007; Martinez et al., 2006). These statistics provide some insight into parent-child relationships that relate to parent and family connectedness in Chile. But the research cited does not measure connectedness directly, attend to connectedness across contexts, or attend to time dimensions, all of which could enhance understanding of Chilean adolescents' connectedness in a manner that holds promise for family research in Chile.

Connection to and engagement with family and school have been identified as important protective factors for Chilean adolescents, particularly with respect to destructive behaviors, drug and alcohol use, and risky sexual behavior (Florenzano, 2002; Magaña Frade \& Meschi Montaldo, 2002). Chilean adolescents who perceive their families to be dysfunctional have a higher prevalence of risk behaviors, emotional symptoms, and premature sexual intercourse than those who do not perceive their families as dysfunctional (Santander et al., 2008). Martinez et al. (2006) condense the findings of government surveys in education, health, and labor, as well as numerous research studies, to illuminate the status of adolescents in Chile. While there is evidence that constructs related to adolescent connectedness with families, peers, and schools are associated with risk and protective factors in Chile, the research to date has not directly measured the connectedness construct or its relationship with risk behaviors among Chilean adolescents. 
In order to understand how connectedness may serve as a protective factor among youth in various cultures, it is first important to clarify the nature of this construct and then to effectively measure it. Too often measures are employed across cultures with no regard to the construct validity of the measure (Bernal, Jiménez-Chafey, \& Domenech Rodríguez, 2009). This is a particularly acute issue in conducting international social science research. At the same time, the universality of certain adolescent risk and protective factors across the world supports a strategy of exploring whether a construct defined within one cultural context is salient for another group in a different context. As such, examining the structure of adolescent connectedness within a group of Chilean adolescents, and how connectedness is related to other risk and protective factors, contributes to establishing the construct validity of connectedness with this population and may inform prevention and intervention efforts with Chilean youth and their families.

In summary, the utility of the Hemingway for measuring adolescent connectedness includes its assessment of both affect and behaviors in specific relationships, contexts, and activities, which is consistent with how the construct is defined and construed in the literature (e.g., Barber \& Schluterman, 2008; Townsend \& McWhirter, 2005); its potential for evaluating interventions, because family and school connectedness commonly are targeted by youth programs (Roth \& Brooks-Gunn, 2003); and third, its promise with respect to predictive validity, because several of the connectedness subscales are inversely associated with risk factors among adolescents in the United States and elsewhere (including drug use, risky sexual behavior, and school attrition) that predict future negative outcomes (Karcher, 2003). The 15 Hemingway subscales fall within four broad conceptual domains of family, friends, school, and self, and the subscales fall under one of three ecological levels that include connectedness to self (including present self and future self), connectedness to others (including friends, parents, father, mother, siblings, teachers, peers, and boyfriend/girlfriend), and connectedness to society (including different cultures, religion, reading, school, and neighborhood).

The primary aim of the present study, then, was to assess the factorial and construct validity of the Hemingway for measuring connectedness among Chilean adolescents. In a measurement invariance study of academic-related connectedness among adolescents in the Unites States and a (different) sample of Chilean adolescents, we found factorial validity for the subscales, but also that some subscales were non-invariant. This suggested that academic-related connectedness is valid to measure among Chilean youth, but that direct score comparisons between Chilean and United States youth on some of the academic-related subscales should not be made (Castro-Villarreal, Sass, McWhirter, McWhirter, \& Karcher, in press). This further highlights the importance of clarifying the factor structure of the full range of subscales on the Hemingway measure specifically among Chilean youth.

Toward this end, in this study we first examined the factor structure of the Hemingway in another sample of Chilean adolescents, as an important step toward understanding the potential universality and cultural specificity of the connectedness construct. Second, we examined correlations between the resulting connectedness factors and a set of common risk and protective factors for adolescent problem behavior in Chile (Florenzano, 2002). These analyses provide initial concurrent and discriminant validity evidence for connectedness as a multidimensional construct and for the utility of the Hemingway with this population.

\section{Method}

\section{Participants}

A total of $4257^{\text {th }}-12^{\text {th }}$ grade students attending the same school participated in a larger data collection, with 390 completing the connectedness measure that is the focus of the present study. School records indicate that over $95 \%$ of students in each grade level participated. The school was a partially-subsidized Catholic school located in urban central Santiago, Chile. Students in this school are in the poor to lower-middle class of the socioeconomic status 
(SES) continuum. Average monthly household income reported by participating parents was about $\$ 380,000$ pesos (US $\$ 760.00$ based on the exchange rate at the time of data collection) per household, with the median income of $\$ 333,000$ pesos (US $\$ 666.00$ ) and the modal monthly income of $\$ 250,000$ pesos (US\$500.00). Tuition cost to families was $\$ 25,000$ pesos (US\$50.00) per month per child. As a means of comparison, according to a report by Celhay, Sanhueza, and Zubizarreta (2009), average income for heads of households in Chile who were between the ages of 28 and 40 and with 12 years of education was US $\$ 813.00$.

Student participants ranged in age from $12-19$ years $(M=15.5, S D=1.84)$. There were 207 male and 183 female participants. Sixty-two percent of the student participants lived with their biological mother and father, 31\% lived with their biological mother, but not with their biological father, $2 \%$ lived with their biological father, but not with their biological mother, and $3.5 \%$ lived with neither their biological mother nor biological father. A national survey of Chilean youth indicates that approximately $65 \%$ of youth ages $15-19$ live with both parents and $20.5 \%$, with their mother only.

Participants also included 376 parents (268 mothers and 108 fathers). With respect to parent education, for mothers $20 \%$ reported their highest level of education was less than a high school degree, 33\% a high school degree, 5\% some technical training, 15\% completed technical training, 5\% reported some college, $2.7 \%$ had completed college (were licenciado), $17 \%$ had a college degree (were titulado), and 2.6\% reported having a graduate degree. For fathers, $18 \%$ reported that their highest level of education was less than a high school degree, 31\% reported completing a high school degree, 3\% had some technical training, 17\% completed technical training, $8.2 \%$ had some college, $2.5 \%$ completed college (were licenciado), $17.5 \%$ had a college degree (were titulado), and 3.4\% reported having a graduate degree. In 2004 nearly half of all adult Chileans did not possess any secondary schooling (Holm-Nielsen, Thorn, \& Prawda, 2004), but education reforms since 1990 have increased educational attainment. In 2008, 78\% of Chileans had completed secondary school by age 24 (Chile, Ministerio de Educación, 2010). Overall, participants in this study had parents with higher average levels of education and lower average reported incomes than Chileans in general.

Teachers $(N=12 ; 6$ male, 6 female) who instructed grades 7-12 (two classrooms and teachers per grade level) completed a teacher inventory of behaviors of the students for each participating adolescent in their primary classroom. One $9^{\text {th }}$ grade classroom teacher opted not to complete the inventories. Teacher experience varied from 5 years to 18 years of teaching.

\section{Measures}

The measures we utilized in this study were part of a larger multi-agent, multi-method research project.

Hemingway Measure of Adolescent Connectedness. The theoretical basis for adolescent connectedness in the Hemingway is rooted in adolescents' need for belongingness and relatedness (Baumeister \& Leary, 1995) and the notion that persons are best understood by understanding their interpretations of connectedness to their different contexts over time (Nakkula \& Selman, 1991). The Hemingway measure was created to assess connectedness in different ecological domains with time as a dimension (Karcher, 2003). The measure was developed systematically using grounded theory approaches, item response theory, and factor analytic studies (Karcher, 2003). An item pool was developed after conducting focus groups with youth in schools and with graduate students familiar with the concepts of connectedness, belongingness, and affiliation. The measure was then tailored to include appropriate language for adolescents (Karcher, 2003). Factor analyses were then used to confirm the underlying structure of the connectedness construct. The resulting final 78 item Hemingway (Karcher, 2003) was designed to assess connectedness among adolescents in the different domains most important to their ecology, including connectedness to parents, religion, peers, school, self, and neighborhood. 
The final version of the measure includes 15 subscales with questions related to both behavior and feelings (e.g., caring) toward the different contexts in which adolescents interact. These 15 subscales fall into three broad dimensions of connectedness: to self, to others, and to society. Connectedness to self includes scales that assess: (a) Present Self, which reflects positive feelings about the self over time and across relationships and the ability to be alone and to tolerate rejection and criticism (Kohut \& Elson, 1987); and (b) Future Self (Nakkula \& Selman, 1991). Connectedness to others includes scales that assess connectedness to: (c) Parents; (d) Mother; (e) Father; (f) Friends; (g) Teachers; (h) Siblings; (i) Peers/Classmates; and (j) Boyfriend/Girlfriend. Connectedness to society includes scales related to: (k) School; (l) Neighborhood/Community; (m) Different Cultures; (n) Reading; and (o) Religion. Sample items include "Spending time with my friends is a big part of my life", "I enjoy spending time with my parents", and "I want to be respected by my teachers." Answers range along a 5-point Likert-type scale anchored by 1 (Not at all true) to 5 (Very true). Karcher (2003) reports adequate to strong internal consistency and evidence of concurrent validity in United States samples, with evidence of validity in an international sample as well (Karcher \& Lee, 2002). Internal consistency for the total scale for the current sample of Chilean adolescents was $\alpha=0.88$.

Youth Questionnaire. Adolescent participants completed a brief standard demographic questionnaire to assess basic information on a number of areas, including SES (family income, parent education and occupation), number of people living in the home, number of rooms in the home, age, sex, and grade level. In addition, we measured adolescent self-reported risk behaviors using measures developed in a national institute of drug abuse, a funded intervention trial referred to as Community Action for Successful Youth (Biglan, Metzler, \& Ary, 1994) and later revised and updated by Connell, Dishion, Yasui, and Kavanagh (2007). These measures have been employed in studying adolescent risk behavior in the United States, Italy, the Netherlands, and Canada (e.g., Boislard, Poulin, Kiesner, \& Dishion, 2009; Venkatraman, Dishion, Kiesner, $\&$ Poulin, 2009). Four subscales from this Youth Survey were used. Alcohol Use $(\alpha=0.55)$ was measured using self-report of how often, in the last month, the youth drank beer, wine, beer or wine mixed with cola (Fanschop or Navegado), or hard alcohol. Response options on a 14-point scale ranged from 0 to 41 or more times in the last month. Problem Behaviors $(\alpha=0.78)$ were assessed by 13 items, each rated on a 6-point Likert-type scale ranging from 1 (never) to 6 (more than 20 times). Example items are "Skipped school without an excuse", "Stole or tried to steal something worth $\$ 2000$ pesos or more", "Purposefully damaged or tried to damage property." Parental Monitoring $(\alpha=0.82)$ was assessed using five items with a 5-point Likerttype response options ranging from 1 (never or almost never) to 5 (always or almost always). An example item is "How often does at least one of your parents know where you are after school?" Positive Family Relations $(\alpha=0.88$ ) was assessed with 11 items, each rated on a 5-point Likerttype scale ranging from 1 (never) to 5 (always). An example item is "I really enjoy being with my parents".

Parent Questionnaire. Parents completed a brief questionnaire which included 39 items related to parent perceptions of the relationship and trust between parent and child, positive family relations, and parental monitoring. The subscale of Positive Family Relations-Parents was selected for the correlation analysis. The Positive Family Relations-Parents subscale was assessed with eight items, each rated on a 5-point Likert-type scale ranging from 1 (never or almost never) to 5 (always). Example items include "I really enjoyed being with my son/daughter," and "I got along really well with my son/daughter". We found an internal consistency of $\alpha=0.85$ for this subscale for mothers, and an internal consistency of $\alpha=0.86$ for this subscale for fathers.

Teacher Questionnaire. Teachers completed the Teacher Measurement of Risk (TMR) instrument. This 44-item measure, based on Soberman (1995) and modified by Stormshak, Dishion, Light, and Yasui (2005), includes items on a variety of risk and positive behaviors that teachers suspect or know youth may be engaged in, including subscales used in this study 
related to three areas: Attention Problems (10 items with an internal consistency $\alpha=0.95$ ), Sadness, Aloneness, or Depression (7 items, $\alpha=0.90)$, and Suspicion of Drug/Alcohol Use (2 items, $\alpha=0.89$ ). Each of the items was rated on a 10-point Likert-type scale ranging from 1 (no problem at all) to 10 (clear and frequent signs). For the Attention Problems subscale a sample item is "Doesn't seem to pay attention or is very easily distracted", for the Sadness, Aloneness, Depression subscale a sample item is "Seems sad or depressed", and for the Suspicion of Drug/Alcohol Use subscale a sample item is "Spends time with other students that I suspect are smoking or using other drugs". Soberman (1995) found that the TMR has high predictive and convergent validity. Research on multiple gating strategies for identifying youth at risk for serious problem behavior revealed teacher ratings of problematic school behavior to be quite predictive of self-reported substance use and court reported delinquency (Dishion \& Patterson, 1992).

Each of these measures has been used and validated outside of the United States.

\section{Procedure}

Active parental consent was obtained as well as participant assent to participate in the study. Measures were administered to students in intact classrooms by the first author and the research assistant during four class periods (results reported here were part of a larger data collection). Consenting parents completed surveys on site during a parent/teacher meeting. Teachers were paid a small stipend to compensate for their time to complete this measure.

Missing data was not imputed for all items due to the meaningfulness of non-responses for many variables. For example, items assessing connectedness to a boyfriend/girlfriend or to a sibling were skipped if the respondent did not have a boyfriend/girlfriend or was an only child, respectively.

The measures were already available in Spanish; however, in order to identify national and regional differences in language, our research assistant reviewed each word of each measure and made minor modifications to ensure language appropriateness for Chilean Spanish speakers. In addition, the Chilean school psychologist/counselor reviewed each item of each measure and approved them with respect to clarity and comprehension for Chilean youth.

\section{Data Analyses}

Inspection of the data indicated that 41 participants did not respond to the items assessing connectedness to Siblings, and 162 did not respond to the items assessing connectedness to Boyfriend/girlfriend. No other subscale items had similar patterns of missing values. We determined that imputation of these items would not be appropriate. Only 113 cases contained complete data for all Hemingway items, a number insufficient for an exploratory factor analysis (EFA) of this measure. Therefore, we dropped the five Sibling and five Boyfriend/girlfriend items and conducted a missing values analysis. Results of the missing values analyses indicated that the data was not missing completely at random, $\left.\chi^{2}(5705, N=425)=6353.8, p<0.001\right)$. Also, missing values analysis of the data revealed that 35 of the 425 total participants did not fill out any items on the Hemingway, indicating that they were not present when that portion of the survey was administered. So it would not be appropriate to impute data on the missing 35 participants. Thus, we imputed the remaining 68 items for the 390 participants who had completed the majority of the items, using the expectation-maximization algorithm. After describing the results of the EFA on the imputed data set, we also describe below the analyses of the Sibling and Boyfriend/girlfriend items.

We conducted the EFA using principal-axis factoring, with a direct oblimin (oblique) rotation. We chose an oblique instead of orthogonal rotation, expecting that factors would be correlated in the present sample as in previous research findings with this measure (Karcher \& Lee, 2002). The Kaiser-Meyer-Olkin (KMO) measure of sampling adequacy was 0.82 and Bartlett's test of sphericity was statistically significant $(p<0.001)$; therefore, we proceeded 
with the factor analysis (Tabachnick \& Fidell, 2001). Multiple criteria were used to evaluate and determine the number of factors to retain, including (a) examination of the scree plot, (b) eigenvalues $>1$, (c) interpretability of the factors, and (d) a minimum of three items loading on the factor (Costello \& Osborne, 2005; Tabachnick \& Fidell, 2001). Upon completion of the factor analysis, we conducted internal consistency reliability analyses for each subscale, calculating Cronbach's alpha, followed by computation of Pearson product-moment correlation with selected criterion variables to assess the construct validity of the measure. For the correlation analyses, we used pairwise deletions to handle missing data on mother and father reports, since parent-reported data was from the mother or the father, but not from both parents.

Finally, we calculated product-moment correlation coefficients between the Hemingway subscales and multi-source data, in order to provide evidence of concurrent and discriminant validity of the Hemingway factors. This correlation matrix included constructs that have been shown to relate to adolescent connectedness in previous research: (a) youth self-reports of alcohol use, problem behaviors, parental monitoring, and positive family relations; (b) teacher reports of their perceptions of the youth as having attention problems, being sad, alone, and depressed, and suspicion that the child uses drugs and/or alcohol; and (c) mother and father reports of positive family relations, or about enjoying spending time with their child.

\section{Results}

The initial results of the EFA on Hemingway data indicated an 18 factor solution based on Kaiser's criterion of eigenvalues above 1.0, and an 11 factor solution based on the scree plot. Five of the 18 factors failed to meet the criteria of possessing three or more items loading at 0.32 or above on the factor (Tabachnick \& Fidel, 2001). Based on this finding, and the fact that Karcher (2003) developed the measure to assess 15 domains of connectedness (that included the Sibling and Boyfriend/girlfriend subscales) and reported a 15 factor solution, we next conducted an EFA constraining the results to a 13 factor solution. We tested a 13 factor solution because we had eliminated the Sibling and Boyfriend/girlfriend subscales. This solution, based on all 68 items, explained $60.4 \%$ of the variance of adolescent connectedness. One factor consisted of four items, of which two had factor coefficients of 0.33 . Given this finding and the scree plot results, we next compared 12 and 11 factor solutions. These explained $58.4 \%$ and $56.3 \%$ of the variance, respectively, and each had seven factor coefficients below 0.32 . The 11 factor solution provided a more interpretable structure; therefore, we retained the 11 factor solution.

The next step in this set of analyses was to eliminate items loading below 0.32 and those that cross-loaded above 0.32 on more than one factor (Tabachnick \& Fidel, 2001). First, we eliminated the seven items with factor loadings below 0.32 , yielding a solution with two cross loading items and two additional items loading below 0.32 . Next, we eliminated these four items, resulting in a 11 factor solution with 57 items that explained $61.92 \%$ of the variance; all factor coefficients were 0.32 or higher and no items cross loaded. We present the results of the final factor analysis with 57 items in Table 1, along with subscale titles.

The subscales obtained in the present sample differed from Karcher's (2003) reported subscales in several ways. First, in the Chilean sample Mother and Parents items formed a single subscale instead of two distinct subscales. Second, in the Chilean sample Present Self and Future Self items formed a single subscale instead of two distinct subscales. Third, one Present Self item loaded on the subscale that otherwise consisted of Peers/Classmates items. Finally, a total of 11 items from a variety of original subscales did not load or cross-loaded on subscales in the Chilean sample and were, therefore, dropped from subsequent analyses.

Based on internal consistency reliability analyses, we deleted one additional item (\#7) from the connectedness to Peers/Classmates subscale, resulting in $\alpha=0.73$ for this subscale. All other alphas were $>0.75$ with the exception of School connectedness $(\alpha=0.63)$, which could not be improved with the exclusion of items. We present the final subscale alpha coefficients in Table 2. 
Table 1

Factorial Solution for the Hemingway Measure of Adolescent Connectedness Among Chilean Youth

\begin{tabular}{|c|c|c|c|}
\hline Factor and item & $\begin{array}{c}\text { Factor } \\
\text { loading }\end{array}$ & Mean & $S D$ \\
\hline Factor 1: Mother/Parents (10 items) & & 3.95 & 0.80 \\
\hline 63. Mi madre y yo somos muy unidas/os. & 0.79 & & \\
\hline 59. Disfruto compartiendo con mi madre. & 0.77 & & \\
\hline 24. Disfruto compartir tiempo con mis padres. & 0.65 & & \\
\hline 44. Mis padres y yo nos llevamos bien. & 0.64 & & \\
\hline 77. Hablo con mi madre acerca de cosas y problemas muy personales. & 0.62 & & \\
\hline 68. Mi madre se preocupa mucho por mí. & 0.57 & & \\
\hline 54. Mis padres me importan mucho. & 0.54 & & \\
\hline 14. Es importante que mis padres confíen en mí. & 0.48 & & \\
\hline 73. Mi madre y yo discutimos mucho. ${ }^{1}$ & 0.47 & & \\
\hline 4. Mi familia y yo nos divertimos juntos. & 0.43 & & \\
\hline \multicolumn{4}{|l|}{ Eigenvalue $=9.32 ;$ Variance explained $=16.35 \%$} \\
\hline Factor 2: Neighborhood (6 items) & & 2.57 & 1.05 \\
\hline 41. Paso mucho tiempo con los jóvenes en mi barrio. & 0.87 & & \\
\hline 11. Me gusta pasar mucho tiempo con los jóvenes de mi barrio. & 0.84 & & \\
\hline 31. A menudo paso tiempo jugando o haciendo cosas en mi barrio. & 0.73 & & \\
\hline 21. Me llevo bien con la mayoría de los jóvenes de mi barrio. & 0.64 & & \\
\hline 51. Mi barrio es aburrido. ${ }^{1}$ & 0.57 & & \\
\hline 1. Me gusta andar por donde vivo en mi barrio. & 0.48 & & \\
\hline \multicolumn{4}{|l|}{ Eigenvalue $=5.09 ;$ Variance explained $=8.94 \%$} \\
\hline Factor 3: Reading (4 items) & & 2.98 & 1.19 \\
\hline 20. Me gusta leer. & 0.91 & & \\
\hline 40. A menudo leo cuando tengo tiempo libre. & 0.86 & & \\
\hline 10. Disfruto dedicar un tiempo para leer solo. & 0.79 & & \\
\hline 30. Nunca leo libros en mi tiempo libre. ${ }^{1}$ & 0.57 & & \\
\hline \multicolumn{4}{|l|}{ Eigenvalue $=4.51 ;$ Variance explained $=7.92 \%$} \\
\hline Factor 4: Friends (6 items) & & 3.85 & 0.90 \\
\hline 42. Paso tanto tiempo como puedo con mis amigos. & -0.77 & & \\
\hline 22. Compartir tiempo con mis amigos es parte importante de mi vida. & -0.76 & & \\
\hline 2. La mejor parte de mi día es cuando estoy con mis amigos. & -0.69 & & \\
\hline 52. Mis amigos/as y yo pasamos mucho tiempo conversando. & -0.63 & & \\
\hline 12. Tengo amigos/as muy cercanos/as en los que confío plenamente. & -0.59 & & \\
\hline 32. Mis amigos/as y yo hablamos abiertamente sobre temas personales. & -0.50 & & \\
\hline \multicolumn{4}{|l|}{ Eigenvalue $=2.73 ;$ Variance explained $=4.78 \%$} \\
\hline Factor 5: Different Cultures (3 items) & & 3.89 & 1.16 \\
\hline 65. Me gustaría conocer más gente de diferentes grupos culturales. & -0.93 & & \\
\hline 60. Me gusta conocer jóvenes de otros grupos culturales. & -0.91 & & \\
\hline 69. Me gusta conocer gente que sea culturalmente diferente a mí. & -0.86 & & \\
\hline \multicolumn{4}{|l|}{ Eigenvalue $=2.50 ;$ Variance explained $=4.38 \%$} \\
\hline Factor 6: Religion (3 items) & & 2.68 & 1.29 \\
\hline 75. Soy una persona religiosa o con fe. & 0.91 & & \\
\hline 62. Mi religión es muy importante para mí. & 0.89 & & \\
\hline 71. Asisto a un servicio religioso (como la iglesia) regularmente. & 0.72 & & \\
\hline Eigenvalue $=2.25 ;$ Variance explained $=3.95 \%$ & & & \\
\hline
\end{tabular}


Factor and item

Factor 7: Teachers (4 items)

38. Trato de llevarme bien con mis profesores.

48. Siempre me esfuerzo por ganarme la confianza de mis profesores.

8. Me importa lo que mis profesores piensen de mí.

50. Casi siempre me gustan mis profesores.

18. Me desagradan varios profesores en mi colegio

Eigenvalue $=2.20 ;$ Variance explained $=3.85 \%$

Factor 8: Present/Future Self (7 items)

53. Tengo intereses o habilidades únicas que me hacen interesante.

29. Realizo actividades fuera del colegio para prepararme para mi futuro.

43. Tengo pasatiempos especiales, habilidades o talentos.

39. Hago muchas cosas para prepararme para mi futuro.

23. Puedo nombrar tres cosas que a los otros chicos les gusta de mí.

49. Pienso constantemente sobre mi futuro.

3. Puedo nombrar cinco cosas que a la gente les gusta de mí.

Eigenvalue $=1.96 ;$ Variance explained $=3.43 \%$

Factor 9: Peers/Classmates (5 items)

47. Le agrado a mis compañeros/as de curso.

37. Me llevo bien con los otros estudiantes de mi curso.

17. Me agradan todos mis compañeros/as de curso.

7. Mis compañeros/as me molestan. ${ }^{1}$

33. Realmente me gusta quien soy.

Eigenvalue $=1.77 ;$ Variance explained $=3.10 \%$

Factor 10: Father (4 items)

64. Mi padre y yo somos muy unidos.

67. Mi padre se preocupa mucho por mí.

58. Disfruto compartiendo con mi padre.

78. Hablo con mi padre acerca de cosas y problemas muy personales.

Eigenvalue $=1.57 ;$ Variance explained $=2.75 \%$

Factor 11: School (5 items)

16. Disfruto estar en el colegio.

3.45

0.70

6. Me esfuerzo en el colegio.

26. Me aburro mucho en el colegio. ${ }^{1}$

0.47

36 . Me va bien en el colegio.

0.39 


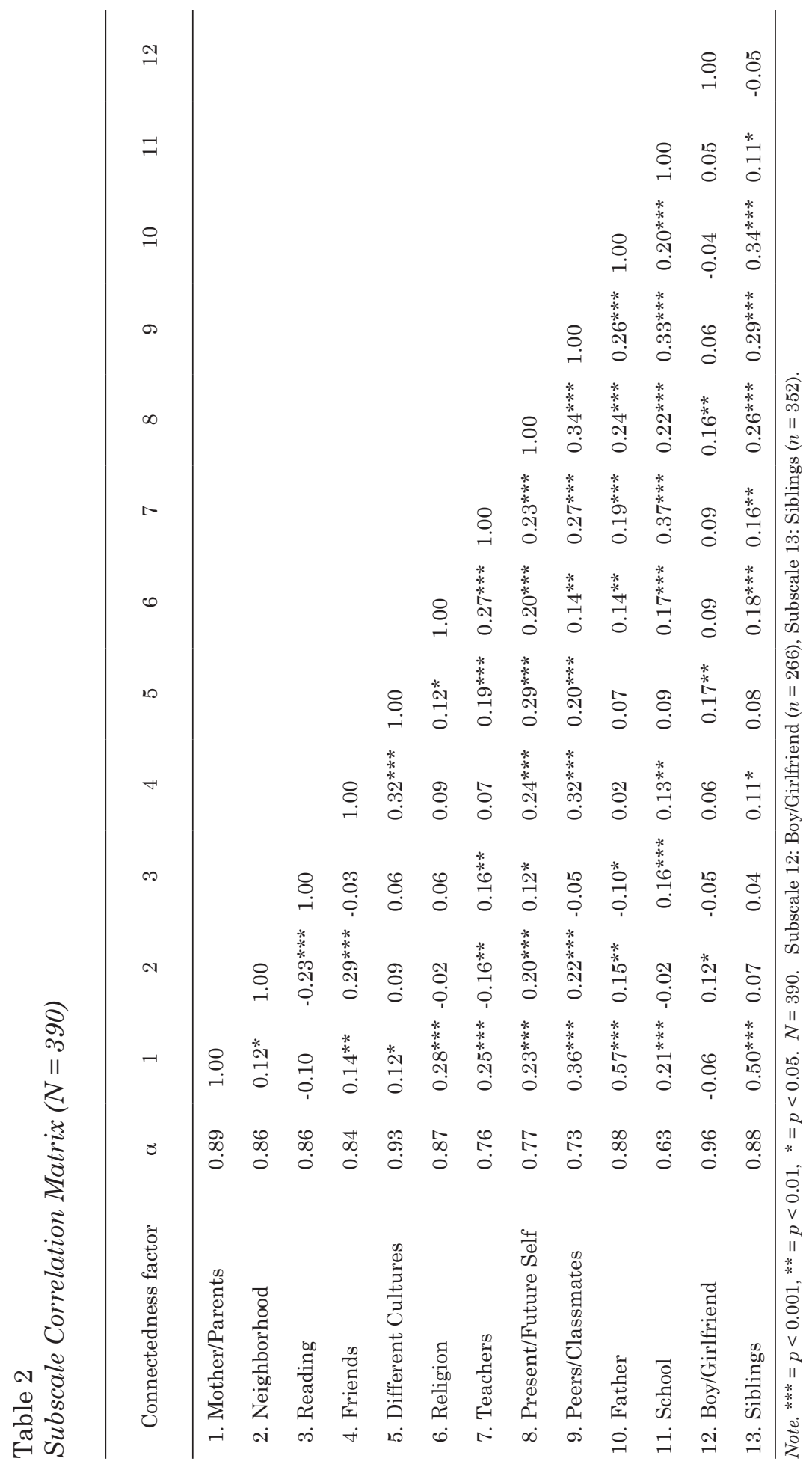


In order to explore the viability of the 5-item connectedness to Boyfriend/girlfriend subscale and the 5-item connectedness to Siblings subscale, we conducted two EFAs with the original non-imputed data set. In the first EFA we used pairwise deletion of cases with missing items and in the second, listwise deletion of cases with missing items. We compared Factor coefficients for the Boyfriend/girlfriend and Sibling connectedness items in each resulting pattern matrix. In each pattern matrix four of the Boyfriend/girlfriend items and the five Sibling items (nine in total) formed separate, distinct, and viable subscales. In each pattern matrix one Boyfriend/girlfriend item did not load with the other Boyfriend/girlfriend items and did not load on another viable factor. This item was negatively worded and reverse coded, and may not have been well understood by participants. In the EFA conducted using pairwise deletion, factor coefficients ranged from 0.92 to 0.93 for the four Boyfriend/girlfriend items and from 0.66 to 0.86 for the five Sibling items. In the EFA conducted using listwise deletion, factor coefficients ranged from 0.92 to 0.94 for the four Boyfriend/girlfriend items and from 0.67 to 0.91 for the five Sibling items. On the basis of these findings, we constructed connectedness to Boyfriend/girlfriend (four items) and connectedness to Siblings (five items) subscales. Internal consistency reliabilities were $0.96(n=214)$ for the connectedness to Boyfriend/girlfriend subscale $(M=2.65, S D=1.53)$ and $0.88(n=337)$ for the connectedness to Siblings subscale $(M=$ $3.72, S D=1.03)$.

We present the subscale correlation matrix among the 13 Hemingway subscales (the 11 Hemingway subscales derived from the EFA of the imputed data and the two Hemingway subscales of Boyfriend/girlfriend and Sibling connectedness) in Table 2. Subscale correlations ranged from 0.02 to 0.57 , suggesting that the subscales measure relatively distinct dimensions of adolescent connectedness. The correlation of greatest magnitude was between the Mother/ Parents and Father subscales (0.57). Overall, the Mother/Parents subscale was correlated with the greatest number of subscales (all but Reading and Boyfriend/girlfriend subscales) while the Boyfriend/girlfriend subscale correlated with the fewest other subscales, specifically only the subscales for Different Cultures, Neighborhood, and Present/Future Self. We present interpretations of these findings in the Discussion.

We present the product-moment correlations between the 13 Hemingway subscales and multi-source data (self report, teacher report, and parent report) in Table 3. These results provide evidence of concurrent and discriminant validity of the Hemingway factors.

As would be predicted from theory and literature on risk behavior, results demonstrated that higher connectedness to Friends, Boyfriend/girlfriend, and to Neighborhood, and that lower connectedness to Mother/Parents, Father, Siblings, Teachers, and School, were all associated with self-reports of alcohol use. A similar pattern was found for self reports of problem behavior, with the addition of significant inverse correlations with connectedness to Religion and Peers/Classmates and no significant correlation between connectedness to Friends and problem behaviors. Parental monitoring was significantly and positively associated with all connectedness subscales except Neighborhood, Friends, Reading, and Different Cultures; self reported positive family relationships were significantly associated with all subscales except Reading. Also consistent with the literature on risk and protective factors, teacher reports of attention problems, sadness, and drug or alcohol use were significantly and inversely associated with connectedness to Mother/Parents, School, Peers/Classmates, and Teachers. Finally, mother and father reports that they enjoy time with their child was significantly associated with Mother/Parents connectedness and Father connectedness, with stronger correlations between mother reports and Mother/Parents connectedness, and father reports and Father connectedness, respectively. 
Table 3

Pearson Product Moment Correlations of Hemingway Connectedness Subscales With Selected Youth, Teacher, and Parent Reported Variables

\begin{tabular}{|c|c|c|c|c|c|c|c|c|c|}
\hline \multirow{2}{*}{$\begin{array}{l}\text { Hemingway factor } \\
\text { Connectedness } \\
\text { related to... }\end{array}$} & \multicolumn{4}{|c|}{ Youth report } & \multicolumn{3}{|c|}{ Teacher report } & \multicolumn{2}{|c|}{ Parent report } \\
\hline & $\mathrm{ALC}$ & PROB & $\begin{array}{l}\text { PAR } \\
\text { MON }\end{array}$ & $\begin{array}{l}\text { POS } \\
\text { FAM }\end{array}$ & ATT & $\mathrm{SAD}$ & $\begin{array}{c}\text { DRUG } \\
\text { ALC }\end{array}$ & M-POS & D-POS \\
\hline & $n=349$ & $n=370$ & $n=370$ & $n=370$ & $n=349$ & $n=349$ & $n=349$ & $n=249$ & $n=100$ \\
\hline Mother/Parent & $-0.18^{* *}$ & $-0.30 * *$ & $0.48^{* *}$ & $0.71^{* *}$ & $-0.13^{*}$ & $-0.16^{* *}$ & $-0.15^{* *}$ & $.21^{* *}$ & $.39 * *$ \\
\hline Neighborhood & $0.11^{*}$ & $0.15^{* *}$ & -0.00 & $0.18^{* *}$ & $-0.12^{*}$ & -0.03 & -0.04 & 0.03 & -0.05 \\
\hline Reading & 0.08 & -0.01 & -0.00 & -0.04 & -0.10 & 0.04 & 0.10 & 0.08 & -0.14 \\
\hline Friends & $0.16^{* *}$ & 0.05 & 0.01 & $0.13^{* *}$ & 0.01 & $-0.12^{*}$ & -0.01 & -0.07 & -0.12 \\
\hline Different Cultures & 0.07 & 0.02 & 0.10 & $0.13^{*}$ & -0.06 & $-0.12^{*}$ & 0.04 & -0.05 & -0.04 \\
\hline Religion & -0.08 & $-0.19^{* *}$ & $0.15^{* *}$ & $0.26^{* *}$ & $-0.20^{* *}$ & $-0.28 * *$ & -0.10 & 0.05 & -0.00 \\
\hline Teachers & $-0.18^{* *}$ & $-0.23^{* *}$ & $0.26^{* *}$ & $0.21^{* *}$ & $-0.34^{* *}$ & $-0.24^{* *}$ & $-0.23^{* *}$ & 0.03 & 0.10 \\
\hline Present/Future Self & 0.07 & 0.03 & $0.18^{* *}$ & $0.30 * *$ & 0.02 & -0.09 & 0.09 & 0.08 & -0.03 \\
\hline Peers/Classmates & 0.00 & $-0.11^{*}$ & $0.20 * *$ & $0.34^{* *}$ & $-0.14^{* *}$ & $-0.23^{* *}$ & $-0.17^{* *}$ & 0.08 & 0.19 \\
\hline Father & $-0.11^{*}$ & $-0.23^{* *}$ & $0.37 * *$ & $0.55^{* *}$ & -0.08 & $-0.17 * *$ & $-0.17 * *$ & $0.14^{*}$ & $0.28^{* *}$ \\
\hline \multirow[t]{2}{*}{ School } & $-0.14^{* *}$ & $-0.17 * *$ & $0.21^{* *}$ & $0.20 * *$ & $-0.27^{* *}$ & $-0.21^{* *}$ & $-0.30 * *$ & 0.08 & 0.05 \\
\hline & $n=237$ & $n=249$ & $n=249$ & $n=249$ & $n=236$ & $n=236$ & $n=236$ & $n=169$ & $n=65$ \\
\hline \multirow[t]{2}{*}{ Boyfriend/Girlfriend } & $0.17 * *$ & 0.08 & -0.04 & -0.11 & 0.10 & 0.00 & 0.11 & -0.05 & -0.20 \\
\hline & $n=314$ & $n=336$ & $n=336$ & $n=336$ & $n=318$ & $n=318$ & $n=318$ & $n=223$ & $n=95$ \\
\hline Siblings & $-0.12^{*}$ & $-0.24^{* *}$ & $0.29^{* *}$ & $0.38^{* *}$ & -0.08 & $-0.18^{* *}$ & -0.05 & -0.01 & $0.25 *$ \\
\hline
\end{tabular}

Note. ALC $=$ Alcohol use, $\mathrm{PROB}=$ Problem behavior, $\mathrm{PAR}$ MON $=$ Parental monitoring, POS FAM $=$ Positive family relations, ATT $=$ Attention problems, $\mathrm{SAD}=\mathrm{Sad}$, alone, depressed, DRUG ALC = Suspects drug and alcohol use, M-POS = Mother reports positive family relations, D-POS $=$ Father reports positive family relations.

$* *=p<0.01,{ }^{*}=p<0.05$.

\section{Discussion}

The factor structure of the Hemingway was highly similar to that reported by Karcher (2003) in regards to both the resultant factors and to the items loading on each factor. In addition to 11 items from Karcher's measure that failed to load or that cross-loaded in the present sample, there were three notable differences in the factor structure. First, in the present study connectedness to mothers and to parents loaded together rather than as separate factors. This may be due to the fact that Chilean youth are more satisfied with their relationships with their mothers, talk with their mothers more, and view their mothers as dedicating enough time to them (Herrera, 2007). This may also reflect other research findings that Chilean mothers are perceived as more caring and more involved with the family, while fathers may be perceived more as authority figures who establish rules but may be less involved emotionally with their children (Martinez et al., 2006; Olavarría, 2003). It may be that the items about connectedness to parents elicited responses to mothers, as they are more likely to express affective connections with their children. These family characteristics, however, are not unique to Chile and are certainly true of youth perceptions and experiences in the United States as well, so perhaps the combined loading of mother and parent items in the present study may be due in part to the number of youth (31\%) who were living with only their mother in a single-parent household. 
A second factor structure difference is that in the Chilean sample items for connectedness to self in the present and connectedness to self in the future loaded together rather than as separate factors. According to the research summarized by Martinez et al. (2006), Chilean adolescents view the development of a personal identity as very important to accomplishing life goals and the building of personal identity is associated with competence and future happiness. These authors further note that Chilean adolescents generally have high self-esteem, positive self-concepts, and optimistic future-oriented aspirations and expectations; they believe that persistence and hard work will lead to future accomplishments and that having a good job or career is a key to future well-being (Martinez et al., 2006). It may be that Chilean adolescents experience a greater sense of continuity and connection between their present and future or that they are more future-oriented than adolescents from the United States. Even among Chilean young people of lower SES, Palacios and Cárdenas (2009) reported that 94.5\% agreed that "education is important for growth as a person" and 88.5\% agreed that "having a good education helps achieve success in life."

The only other difference between Karcher's reported factor structure and the present results was that one item of connectedness to self in the present ("I really like who I am") loaded on the Classmates/peers subscale rather than the Self in the Present/future subscale. While this item had a relatively low loading (0.32), perhaps it reflects an important notion in peer relationships that, for some adolescents, self-acceptance may be based in part on external feedback, inclusion with, and acceptance from others. In part, youth may experience self-liking as a function of how much they like and are liked by their peers. This interpersonal dimension of the sense of self is clearly grounded in and supported by the research literature on adolescent development, belongingness, affiliation, and connectedness (Karcher, 2003; Saraví, 2009; Townsend \& McWhirter, 2005).

The results of the correlation analyses between connectedness subscales and adolescent, parent, and teacher variables revealed some interesting relationships that are theoretically consistent. The results indicated that students reporting more problem behavior (including lying to parents, hitting or threatening someone at school, damaging property, and carrying weapons) were also less connected to their families (mother/parents, siblings, fathers), teachers, and schools, but were more connected to their neighborhoods. Resnick et al. (1997) found parent/family connectedness and school connectedness to be protective factors for adolescents of the Unites States in relation to their engagement in violence, substance use, sexual behavior, and emotional health. Karcher and Finn (2005) found that connectedness to parents decreased the likelihood of experimental smoking in rural adolescents. The pattern of correlations found in this investigation, in conjunction with existing literature on Chilean youth (e.g., Florenzano, 2002; Martinez et al., 2006; Santander et al., 2008), suggest that connectedness to family may be a strong protective factor in Chile and, as such, may be an important focus of prevention and intervention efforts.

Also consistent with the literature on risk and protective factors among youth in the Unites States and in other countries, students in this study who reported higher parental monitoring of their behavior were also more connected to their families (mother/parent, siblings, father), as well as to their religion, peers, teachers, and schools. Parental monitoring is widely regarded as a protective factor for adolescents, associated with lower rates of association with deviant peers, substance use, and problem behaviors (Dishion et al., 2008). In Chile, both mothers' and fathers' monitoring of their adolescents is associated with higher adolescent self-efficacy and achievement orientation, while parental punitiveness has been shown to have the opposite effect (Ingoldsby, Schvaneveldt, Supple, \& Bush, 2005). Parent reports of enjoying time with their child were associated with higher connectedness to both parents, and for fathers, reports of enjoying time with the child was associated with higher connectedness to siblings. Parent enjoyment of time with their child was not associated with any other domains of connectedness. The strongest correlate of connectedness to self in the present/future was the adolescent's report of positive family relationships. These findings are all consistent with the importance and centrality of the family in the lives and well-being of Chilean adolescents (Herrera, 2007; Martinez et al., 2006). 
Related to the finding on teacher's perceptions, students with lower connectedness to school, teachers, and peers were also more likely to be viewed by their teachers as having attention problems, being sad/alone, and to be suspected of drug and/or alcohol use. Karcher (2004) and Castro-Villarreal et al. (in press) described connectedness to school as an important element in school violence prevention. Connectedness to peers was more predictive of risk and protective factors than connectedness to friends. Perhaps this is because connectedness to friends defines friendship (if not connected, they would not be considered friends) whereas connectedness to peers in school is more variable. Chilean adolescents of lower SES are less likely to have friends in school and more likely to have friends in the neighborhood (Chile, Instituto Nacional de la Juventud, 2004; Martinez et al., 2006). Martinez et al. (2006) report that there has been little research conducted on peers and peer influences in Chile, and so this area merits further research attention. We were intrigued that connectedness to boyfriend/girlfriend was correlated only with alcohol use. This may simply reflect that both dating and alcohol use tend to increase with age.

Youth with higher connectedness to religion were less likely to be perceived as sad, alone, or depressed by their teachers, and were more likely to report positive family relationships. The majority of Chilean adolescents believe in God (95\%), about 32\% attend weekly church services, and about $20 \%$ of 15-18 year olds participate in religious groups (Martinez et al., 2006). A national survey indicated that about $17 \%$ of Chilean youth believe that religion is "very important" with another $29 \%$ indicating that it is "important", and only $14 \%$ indicated that religion is not at all important (compared with $29 \%$ of youth who thought that politics were not at all important; Baeza, 2007). This finding demonstrates both that teachers are able to notice which youth seem to be involved, engaged, and less depressed, and that their perceptions of students, in fact, match fairly well with adolescents' own reports of being engaged with family, church, and religion, all of which have been identified as protective factors in preventing risk and enhancing healthy outcomes for youth (McWhirter, McWhirter, McWhirter, \& McWhirter, 2007).

Connectedness to reading and to different cultures was not strongly related to any of the correlates examined here. Questions related to different cultures are less relevant to the average Chilean adolescent, who tends to identify strongly nationally as Chilean but less to their different ethno-cultural roots. These questions may elicit different responses from youth in the south or north of Chile, where there is a much stronger indigenous presence. So, although these domains of connectedness may be worth exploring in future research, we recommend only using these subscales when questions of interest relate specifically to these constructs. This would be consistent with the work done by Karcher and Sass (2010), presented in their most recent 57 item version of the Hemingway with 10 subscales, based on a United States sample.

Overall, correlations between Hemingway subscales and the student, teacher, and parent constructs measured here suggest that connectedness is significantly associated with a variety of risk and protective factors among Chilean adolescents in a manner consistent with previous empirical findings. Internal consistency of the subscales was also moderate to strong. These findings provide initial support for the reliability and validity of the Hemingway as a measure of connectedness among Chilean youth. Martínez's (2007) review of adolescent development in Chile calls for increased attention to how daily life contexts shape the competencies and skills of adolescents, particularly those at risk. Adolescent ecologies include home, school, and neighborhood contexts that interact with individual characteristics and contribute to risk and resilience. She emphasizes that there is little research investigating the process and products of adolescents' connectedness with the social institutions around them, or of how those involvements promote their competencies. The Hemingway may be particularly useful in future research addressing the development of competencies among Chilean adolescents because of the multidimensional nature of connectedness and the centrality of connectedness to adolescent well-being, as supported by findings here. The measure may be useful in assessing the effectiveness of interventions designed to enhance adolescents' connectedness with their families, schools, and communities (Gómez, Muñoz, \& Haz, 2007; Martínez, 2007). Moreover, current 
efforts in Chile to support adolescent life-skills and vocational development may also benefit from greater attention to building and assessing connectedness (McWhirter \& McWhirter, in press).

The present findings provide initial support for the utility and validity of the Hemingway in Chile. Overall, the pattern of significant and non-significant correlations is consistent with the theoretical underpinnings of the measure. Adolescents who experience greater connectedness and belonging within family and school are at lower risk for problem behaviors and are less likely to be perceived by their teachers as having emotional or attention problems. Parent enjoyment of time with their child is not a function of the child's connectedness in other domain areas but is related to the child's connectedness to the parents. The pattern of findings is also consistent with empirical literature on adolescent risk and protective factors both in the United States and in Chile. Relationships that would be predicted based on theoretical and empirical literature between the factor subscales and participant self-reports, teacher reports, and parent reports, were supported in the present study.

A limitation of the present study is that participants in this Catholic school sample may be more engaged in religious practices and have higher family involvement than adolescents in public or non-Catholic school settings. In order to increase confidence in the generalizability of the findings, the factor structure of the Hemingway should be investigated with Chilean students attending public and non-religious private schools. Additional future research on the measure also should include studies that concurrently test the factor structure and measurement invariance of the Hemingway across international samples. Such research is needed before comparisons of scores across cultures and national contexts can be reliably made (Castro-Villarreal et al., in press).

Findings from the present study suggest that the 57 items on the 11 factor structure, plus the nine items from two additional factors, constitute a 66-item, 13-factor Hemingway Measure of Adolescent Connectedness that is an effective measure of connectedness across numerous domains of Chilean adolescent life. The Hemingway may be a very useful instrument in future research focused on reducing risk and improving youth, family, school, and social well-being in Chile.

\section{References}

Baeza, J. (2007). Valores y valoraciones presentes en los jóvenes chilenos. Revista Observatorio de Juventud, 15, 60-68. Retrieved from http://200.68.29.91/cedoc/revistas\%20observatorios/2007/revistaobservatorioed15.pdf

Barber, B. K. \& Schluterman, J. M. (2008). "Connectedness" in the lives of children and adolescents: A call for greater conceptual clarity. Journal of Adolescent Health, 43, 209-216. doi:10.1016/j.jadohealth.2008.01.012

Baumeister, R. F. \& Leary, M. R. (1995). The need to belong: Desire for interpersonal attachments as a fundamental human motivation. Psychological Bulletin, 117, 497-529. doi:10.1037/0033-2909.117.3.497

Bernal, G., Jiménez-Chafey, M. I., \& Domenech Rodríguez, M. M. (2009). Cultural adaptation of treatments: A resource for considering culture in evidence-based practice. Professional Psychology: Research and Practice, 40, 361-368. doi:10.1037/a0016401

Beyers, W., Goossens, L., Vansant, I., \& Moors, E. (2003). A structural model of autonomy in middle and late adolescence: Connectedness, separation, detachment, and agency. Journal of Youth and Adolescence, 32, 351-365. doi:10.1023/A:1024922031510

Biglan, A., Metzler, C. W., \& Ary, D. V. (1994). Increasing the prevalence of successful children: The case for community intervention research. The Behavior Analyst, 17, 335-351.

Boislard, M. A., Poulin, F., Kiesner, J., \& Dishion, T. J. (2009). A longitudinal examination of risky sexual behaviors among Canadian and Italian adolescents: Considering individual, parental, and friend characteristics. International Journal of Behavioral Development, 33, 265-276. doi:10.1177/0165025408098036

Bronfenbrenner, U. (1979). The ecology of human development: Experiments by nature and design. Cambridge, MA: Harvard University Press.

Castro-Villarreal, F., Sass, D., McWhirter, B. T., McWhirter, E. H., \& Karcher, M. J. (in press). A cross-cultural assessment of school connectedness: Testing factor invariance with United States and Chile adolescents. Journal of Psychoeducational Assessment.

Celhay, P. Sanhueza, C., \& Zubizarreta, J. R. (2009). Intergenerational mobility of income: The case of Chile 1996 2006 (Working Paper). Washington, DC: ILADES-Georgetown University, School of Economics and Business. Retrieved from http://fen.uahurtado.cl/wp/wp-content/uploads/2010/07/inv237.pdf 
Chile, Instituto Nacional de la Juventud (2004). La integración social de los jóvenes en Chile 1994-2003. Cuarta Encuesta Nacional de la Juventud. Santiago, Chile: Ministerio de Planificación y Cooperación. Retrieved from http://www.scribd.com/doc/17386492/INJUV-CHILE-Cuarta-Encuesta-Nacional-de-Juventud

Chile, Ministerio de Educación (2010). Indicadores de la educación 2004-2008. Santiago, Chile: Author. Retrieved from http://w3app.mineduc.cl/mineduc/ded/documentos/Indicadores_2007-2008.pdf

Clark, K. E. \& Ladd, G. W. (2000). Connectedness and autonomy support in parent-child relationships: Links to children's socioemotional orientation and peer relationships. Developmental Psychology, 36, 485-498. doi:10.1037/00121649.36.4.485

Connell, A. M., Dishion, T. J., Yasui, M., \& Kavanagh, K. (2007). An adaptive approach to family intervention: Linking engagement in family-centered intervention to reductions in adolescent problem behavior. Journal of Consulting and Clinical Psychology, 75, 568-579. doi:10.1037/0022-006X.75.4.568

Costello, A. B. \& Osborne, J. W. (2005). Best practices in exploratory factor analysis: Four recommendations for getting the most from your analysis. Practical Assessment, Research \& Evaluation, 10, Article 7. Retrieved from http:// pareonline.net/getvn.asp?v=10\&n=7

Dishion, T. J., Bullock, B. M., \& Kiesner, J. (2008).Vicissitudes of parenting adolescents: Daily variations in parental monitoring and the early emergence of drug use. In M. Kerr, H. Stattin, \& R. C. M. E. Engels (Eds.), What can parents do? New insights into the role of parents in adolescent problem behavior (pp. 113-133). Chichester, England: John Wiley \& Sons.

Dishion, T. J. \& Patterson, G. R. (1992). Age effects in parent training outcome. Behavior Therapy, 23, $719-729$. doi:10.1016/S0005-7894(05)80231-X

Dwairy, M., Achoui, M., Abouserie, R., \& Farah, A. (2006). Adolescent-family connectedness among Arabs: A second cross-regional research study. Journal of Cross-Cultural Psychology, 37, 248-261. doi:10.1177/0022022106286923

Evans, D. L., Foa, E. B., Gur, R. E., Hendin, H., O’Brien, C. P., Seligman, M. E. P., \& T. Walsh (Eds.). (2005). Treating and preventing adolescent mental health disorders: What we know and what we don't know. New York, NY: Oxford University Press.

Florenzano, R. (2002). El adolecente y sus conductas de riesgo (2 ${ }^{\text {nd }}$ ed.). Santiago, Chile: Ediciones Universidad Católica.

Gómez, E., Muñoz, M. M., \& Haz, A. M. (2007). Familias multiproblemáticas y en riesgo social: Características e intervención. Psykhe, 16(2), 43-54. doi:10.4067/S0718-22282007000200004. Retrieved from http://www.scielo.cl/ scielo.php?script=sci_arttext\&pid=S0718-22282007000200004\&lng=es\&nrm=iso\&tlng=es

Grossman, J. B. \& Bulle, M. J. (2006). Review of what youth programs do to increase the connectedness of youth with adults. Journal of Adolescent Health, 39, 788-799. doi:10.1016/j.jadohealth.2006.08.004

Grotevant, H. D. \& Cooper, C. R. (1998). Individuality and connectedness in adolescent development: Review and prospects for research on identity, relationships, and context. In E. Skoe \& A. von der Lippe (Eds.), Personality development in adolescence: A cross national and life span perspective (pp. 3-37). New York, NY: Routledge.

Herrera, M. S. (2007). Configuraciones familiares y calidad de las relaciones familiares entre los jóvenes chilenos. Revista Observatorio de Juventud, 15, 40-49. Retrieved from http://200.68.29.91/cedoc/revistas\%20observatorios/ 2007/revistaobservatorioed15.pdf

Holm-Nielsen, L., Thorn, K., \& Prawda, J. (2004). Chile: Decades of educational reform deliver. World Bank En Breve, $44,1-4$

Huiberts, A., Oosterwegel, A., Vandervalk, I., Vollebergh, W., \& Meeus, W. (2006). Connectedness with parents and behavioural autonomy among Dutch and Moroccan adolescents. Ethnic and Racial Studies, 29, 315-330. doi:10.1 080/01419870500465553

Ingoldsby, B., Schvaneveldt, P., Supple, A., \& Bush, K. (2005). The relationship between parenting behaviors and adolescent achievement and self-efficacy in Chile and Ecuador. In G. W. Peterson, S. K. Steinmetz, \& S. M. Wilson (Eds.), Parent-youth relations: Cultural and cross-cultural perspectives (pp. 129-148). Florence, KY: Routledge.

Karcher, M. J. (2003). The Hemingway: Measure of adolescent connectedness. A manual for scoring and interpretation. Unpublished manuscript, The University of Texas at San Antonio, TX. Retrieved from www. adolescentconnectedness.com

Karcher, M. J. (2004). Connectedness and school violence: A framework for developmental interventions. In E. R. Gerler Jr. (Ed.), Handbook of school violence (pp. 7-42). Binghamton, NY: The Haworth Press.

Karcher, M. J. \& Finn, L. (2005). How connectedness contributes to experimental smoking among rural youth: Developmental and ecological analyses. The Journal of Primary Prevention, 26, 25-36. doi:10.1007/s10935-0040989-6

Karcher, M. J. \& Lee, Y. (2002). Connectedness among Taiwanese middle school students: A validation study of the Hemmingway Measure of Adolescent Connectedness. Asia Pacific Education Review, 3, 92-114.

Karcher, M. J. \& Sass, D. (2010). A multicultural assessment of adolescent connectedness: Testing measurement invariance across gender and ethnicity. Journal of Counseling Psychology, 57, 274-289. doi:10.1037/a0019357

Kohut, H. (1977). Restoration of the self. New York, NY: International Universities Press.

Kohut, H. \& Elson, M. (1987). The Kohut seminars on self psychology and psychotherapy with adolescents and young adults. New York, NY: W. W. Norton.

Kohut, H. \& Wolf, E. S. (1978). The disorders of the self and their treatment: An outline. International Journal of Psychoanalysis, 59, 413-425.

Kumi-Kyereme, A., Awusabo-Asare, K., Biddlecom, A., \& Tanle, A. (2007). Influence of social connectedness, communication and monitoring on adolescent sexual activity in Ghana. African Journal of Reproductive Health, 11(3), 133-147. 
Magaña Frade, I. \& Meschi Montaldo, A. (2002). Percepciones, funciones y significados del consumo de drogas en jóvenes escolares del sector oriente de Santiago. Revista de Psicología Universidad de Chile, 11(2), 125-140.

Martínez, M. L. (2007). Mirando al futuro: desafíos y oportunidades para el desarrollo de los adolescentes en Chile. Psykhe, 16(1), 3-14. doi:10.4067/S0718-22282007000100001. Retrieved from http://www.scielo.cl/scielo. php?script=sci_abstract\&pid=S0718-22282007000100001\&lng=es\&nrm=iso\&tlng=es

Martinez., M. L., Cumsille, P., \& Thibaut, C. (2006). Chile. In J. J. Arnett (Ed.), International encyclopedia of adolescence (pp. 167-178). New York, NY: Routledge.

McWhirter, E. H. \& McWhirter, B. T. (in press). Critical perspectives on adolescent vocational guidance in Chile. Journal of Career Development.

McWhirter, J. J., McWhirter, B. T., McWhirter, E. H., \& McWhirter, R. J. (2007). At-risk youth: A comprehensive response ( $4^{\text {th }}$ ed.). Pacific Grove, CA: Brooks/Cole.

Nakkula, M. \& Selman, R. (1991). How people "treat" each other: Pair therapy as a context for the development of interpersonal ethics. In J. L. Gewirtz \& W. M. Kurtines (Ed.), Handbook of moral behavior and development, Vol. 3: Application (pp. 179-211). Hillsdale, NJ: Lawrence Erlbaum Associates.

Olavarría, J. (2003). Men at home? Child rearing and housekeeping among Chilean working class fathers. In M. C. Gutman (Ed.), Changing men and masculinities in Latin America (pp. 333-349). Durham, NC: Duke University Press.

Palacios, M. \& Cárdenas, A. (2009). Empleabilidad juvenil y ambigüedad normativa. Revista Observatorio de Juventud, 21, 63-72. Retrieved from http://200.68.29.91/cedoc/novedades/Trabajo_Empleabilidad_y_Juventud_Edicion_No_ 21_marzo_2009.pdf

Resnick, M. D., Bearman, P. S., Blum, R. W., Bauman, K. E., Harris, K. M., Jones, J. ... Udry, J. R. (1997). Protecting adolescents from harm: Findings from the National Longitudinal Study on Adolescent Health. JAMA The Journal of the American Medical Association, 278, 823-832. doi:10.1001/jama.1997.03550100049038

Roth, J. L. \& Brooks-Gunn, J. (2003). What exactly is a youth development program? Answers from research and practice. Applied Developmental Science, 7, 94-111. doi:10.1207/S1532480XADS0702_6

Santander, S., Zubarew, T., Santelices, L., Argollo, P., Cerda, J., \& Bórquez, M. (2008). Influencia de la familia como factor protector de conductas de riesgo en escolares chilenos. Revista Médica de Chile, 136, 317-324. doi:10.4067/ S0034-98872008000300006

Saraví, G. A. (2009). Youth and feelings of belonging in Latin America: Causes and risks of social fragmentation. Cepal Review, 98, 47-64.

Soberman, L. H. (1995). Psychometric validation of a brief teacher screening instrument. Dissertation Abstracts International: Section A. The Humanities and Social Sciences, 56(2-A), 0514.

Stormshak, E. A., Dishion, T. J., Light, J., \& Yasui, M. (2005). Implementing family-centered interventions within the public middle school: Linking service delivery to change in student problem behavior. Journal of Abnormal Child Psychology, 33, 723-733. doi:10.1007/s10802-005-7650-6

Tabachnick, B. G. \& Fidell, L. S. (2001). Using multivariate statistics. Boston, MA: Allyn and Bacon.

Townsend, K. C. \& McWhirter, B. T. (2005). Connectedness: A review of the literature with implications for counseling, assessment, and research. Journal of Counseling \& Development, 83, 191-201.

Venkatraman, S., Dishion, T. J., Kiesner, J., \& Poulin, F. (2009). Cross-cultural analysis of parental monitoring and adolescent problem behavior: Theoretical challenges of model replication when East meets West. In V. GuilamoRamos, J. Jaccard, \& P. Dittus (Eds.), Parental monitoring of adolescents (pp. 90-123). New York, NY: Columbia University Press.

von der Lippe, A. L. \& Amundsen, E. (1998). Individuation, ego development and the quality of conflict negotiation in the family of adolescent girls. Scandinavian Journal of Psychology, 39, 25-31.

World Health Organization (2003). Skills for health. Skills-based health education including life skills: An important component of a child-friendly/health promoting school (Information Series on School Health, Document 9). Genève, Switzerland: Author. Retrieved from http://www.who.int/school_youth_health/media/en/sch_skills4health_03.pdf

Fecha de recepción: Enero de 2010.

Fecha de aceptación: Marzo de 2011. 